\title{
Relation between Vascular Endothelial Markers and Right Ventricular Function in the Children with Asthma
}

\author{
Mecnun Cetin,, ${ }^{1,}$ Bertan Karaboga, ${ }^{2}$ Ozge Yilmaz, ${ }^{3}$ Munevver Yilmaz, ${ }^{1}$ Hasan Yuksel, ${ }^{3}$ and Senol \\ Coskun $^{1}$ \\ ${ }^{1}$ Celal Bayar University, Department of Pediatric Cardiology, Manisa, Turkey \\ ${ }^{2}$ Celal Bayar University, Department of Pediatrics, Manisa, Turkey \\ ${ }^{3}$ Celal Bayar University, Department of Pediatric Allergy and Pulmonology, Manisa, Turkey \\ "Corresponding author: Dr. Mecnun Cetin, Yuzuncu Yil University, Department of Pediatric Cardiology, Van, Turkey. Tel: +90-4322150473, E-mail: drmecnun@hotmail.com
}

Received 2016 October 16; Revised 2017 April 30; Accepted 2017 June 05.

\begin{abstract}
Objectives: The aim of the study was to evaluate the possible relationship of clinical severity during asthmatic exacerbation with the ventricular functions and the levels of vascular endothelial-related biomarkers endothelin-1 (ET-1) and platelet-derived growth factor-BB (PDGF-BB) in the condensed breathing air in the children with asthma.

Methods: The study included a total of 80 children with acute asthmatic episode; of these, 28 had a mild, 26 had a moderate, and 26 had a severe attack. Samples of condensed breathing air were obtained for being analyzed for ET-1 and PDGF-BB levels during the study. All patients were evaluated by echocardiography at the beginning of the study and two weeks after the treatment of asthmatic episode.

Results: Before treatment, mPAP in moderate and severe asthma groups was significantly higher than in mild asthma group (21.6 $\pm 7.3,30.1 \pm 9.8$ and $32.7 \pm 7.8 ; \mathrm{P}<0.01, \mathrm{P}<0.001$, respectively). After treatment, no significant difference was detected between the asthma groups $(\mathrm{P}>0.05)$. Am and Em waves, and IVRT, IVCT, ET and RV MPI during the asthmatic attack and after treatment did not change significantly between the groups; pre- and post-treatment values of these parameters also did not show significant differences. In exhaled air samples of the group with severe asthma exacerbation ET-1 and PDGF-BB were higher than those in the moderate and mild group $(0.80 \pm 0.42,0.58 \pm 0.30,0.50 \pm 0.15 ; \mathrm{P}=0.002$ and $281.7 \pm 253.2,167.3 \pm 148.1,135.9 \pm 74.9 ; \mathrm{P}=0.008$ respectively).

Conclusions: Our study results showed that mPAP in direct proportion with the increased inflammatory cytokines was significantly higher in asthma attacks and levels of ET-1 and PDGF-BB were significantly increased with severity of asthma, indicating a vascular response.
\end{abstract}

Keywords: Asthma, Doppler Echocardiography, Endothelin-1, Platelet-Derived Growth Factor-BB, Ventricular Function

\section{Background}

Asthma is a frequently existing chronic inflammatory disease that both genetic and environmental factors play a role in, and that affects the inflammatory cells and mediators of the airways (1). During an asthma attack, dramatic changes develop which may affect the heart, the whole body, and primarily the pulmonary bronchospasm. Hypoxia is one of the major changes during the episode (2). Hypoxia causes pulmonary vasoconstriction, which leads to increased right ventricle load, and, thus, cardiac dysfunction in the course of time. Another change during an episode is the increased mediators of inflammation, and the effects of these mediators on the pulmonary bed and the myocardium $(3,4)$. Cytokines that lead to constriction of the airways and vascular epithelium at the time of episode are primarily the endothelin (ET) and plateletderived growth factor (5).
Condensed breathing air/exhaled breath condensate (EBC) is a non-invasive method and it is the collection of cooled breathing air. Exhaled breath condensate has been used in various studies to evaluate indicators specific to the airway diseases in children and has been proven to be reliable (6). Analysis of endothelin and PDGF in the condensed breathing air (EBC) is the way of determining the existing damage by these effective mediators and it is a clinically valuable method $(5,7)$. There is a small number of studies evaluating the ventricle functions by Tissue Doppler imaging (TDI) in asthmatic children. The aim of our study was to investigate the ventricle functions by Doppler echocardiography (DE) in children with asthma attacks in different degrees of severity and to investigate the importance of TDI in determining early ventricular dysfunction in the subclinical period, as well as to investigate whether there is a relationship between the 
Doppler echocardiographic parameters and disease severity, and to indicate if any effect exists on the mediators like endothelin-1(ET-1) and PDGF-BB correlating with the attack severity.

\section{Methods}

This cross-sectional study was conducted in children referred to the Pediatric Pulmonary and Allergy Clinic with an acute asthma attack. The children were being followed with the diagnosis of asthma according to the international guide for the diagnosis and treatment of asthma (8). Our study group included a total of 80 children between the ages of 6 and 15 years who were diagnosed with an acute asthmatic attack based on the clinical signs and laboratory results.

The following criteria were used for exclusion: any pathology causing upper airway obstruction, acquired or congenital heart diseases, primary pulmonary hypertension, obesity, systemic disease and genetic syndrome.

All patients with asthma were questioned for the annual number of attacks, the presence of allergic diseases such as atopic dermatitis and allergic rhinitis associated with asthma, and the positivity of specific IgE. The patients underwent pulmonary function tests. Spirometric evaluations were performed using the Spirobank G (Rome, Italy) device for respiratory function tests (RFT). Measurements by RFT device were administered at room temperature, in the sitting position and by clicking the nose with a latch. Each measurement was repeated three times and the most reliable values were selected. Spirometric evaluations of the forced expiratory volume in one second (FEV1), peak expiratory flow (PEF), forced vital capacity (FVC), and forced expiratory volume in one second/forced vital capacity (FEV1/FVC) values were used. The Global Initiative for Asthma Guidelines (GINA) was used to determine clinical severity of the asthma (8). Twenty-eight patients had a mild asthma attack, 26 had a moderate, and 26 had a severe asthma attack. All children enrolled had acute asthma exacerbation and received inhaled steroid, inhaled beta2 agonist as bronchodilator and systemic steroids for three days. Inhaled steroids were included in their long term treatment and were continued until asthma exacerbation was over clinically.

\subsection{Obtaining and Analysis of the Condensed Breathing Air Samples}

Device for condensed breathing air condensate (Ecoscreen; Jaeger, Hoechberg, Germany) was used for obtaining condensed breathing air (EBC) samples of the patients; the subjects had to inhale and exhale normally into the device for 10 minutes without using nose tongs, and the fluid volume of the breath was collected. EBC measurements were performed considering the recommendations of ERS/ATS (6). The procedure was started following a 2hour fasting, after gargling. Fluid volume of the breath was collected by this method. Accumulated fluid portions of the collected air were transferred into the translucent Eppendorf tubes of $130 \mu \mathrm{L}$ volume that are made up of polypropylene, and the samples were stored at $80^{\circ} \mathrm{C}$ till the assay day. ET-1 and PDGF-BB levels were analyzed in the EBC fluid. Serum PDGF-BB and ET-1 values were tested by ELISA method, using commercial kits (Human PDGF-BB Platinum, Vienna, Austria and Enzyme Immunoassay for the quantitative determination of human endothelin-1, Vienna, Austria, respectively). Following the EBC measurements, the patients were investigated by conventional echocardiography and TDI. Control echocardiographic evaluations were repeated 15 days after the asthmatic attack treatments.

\subsection{Echocardiography}

The ultrasound device of GE-Vingmed Vivid 7 system (GE-Vingmed Ultrasound AS, Horten, Norway) and 3S-RS probe $(3.5 \mathrm{MHz})$ were used for echocardiographic investigation in left lateral decubitus and supine position. The 2D, M-mode and Doppler echocardiographic techniques were used to take the images from parasternal and apical positions. IVS measurement was done through the parasternal long axis at the end of diastole. RV size measurement was taken in apical $4 \mathrm{C}$ sight basally between septum at the level of the tricuspid valve and RV anterior wall (basal diameter) at the end of diastole and systole. RV global systolic function was examined as the tricuspid annular plane systolic excursion (TAPSE) by the two dimensional difference of the end-diastolic and end-systolic lines located between the center of the ultrasound fan origin and the junction of the RV lateral tricuspid annulus in the apical $4 \mathrm{C}$ sight (9). The pulmonary acceleration time (PAcT) was measured using the pulse wave Doppler with the pulse wave sample volume placed within the RV outflow tract. PAcT is the time interval between the onset of the systolic velocity and the peak systolic velocity (10). The mean pulmonary artery pressure (MPAP) was calculated by the equation (Mahan formula $):$ mPAP $=79-(0.45 \times$ PAcT $)(11,12)$. The Mahan formula has been investigated and found to have a good correlation in the measurement of mPAP when compared to direct invasive catheterization method (13). TDI was assessed from the apical $4 \mathrm{C}$ view with the pulse wave Doppler sample volume traced on the tricuspid lateral annulus. Peak early (Em) and peak late (Am) diastolic myocardial annular velocity, ejection time (ET), isovolumic contraction time (IVCT), and isovolumic relaxation time (IVRT) 
were obtained. Myocardial performance index (MPI) was measured with the Tei index formula (Figure 1) $(14,15)$. The study approved by local ethics committee. The parents of participants signed the informed consent.

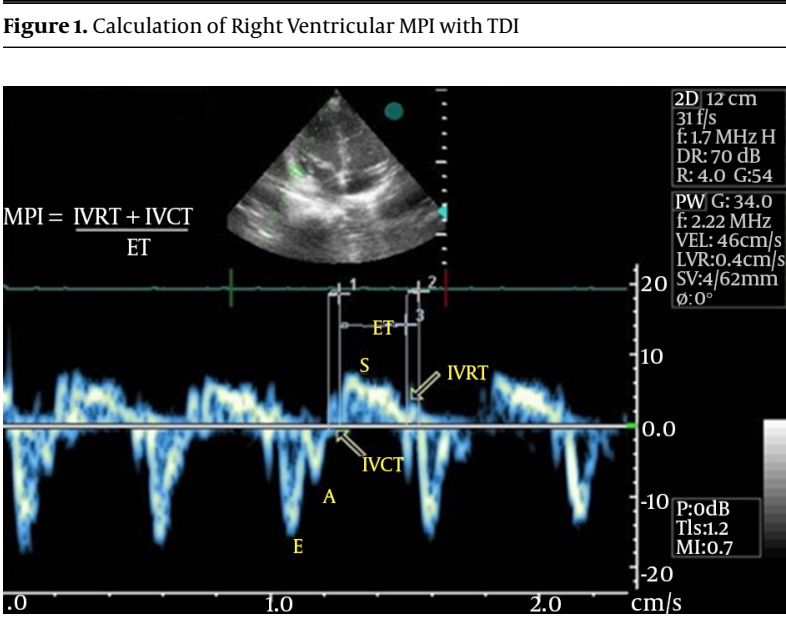

IVRT, isovolumic relaxation time; IVCT, isovolumic contraction time; ET, ejection time; MPI, myocardial performance index.

\subsection{Statistical Analysis}

The statistical analyses were performed using the statistical package for social sciences v15.0 (SPSS15.0). In descriptive statistical analysis of the data, sociodemographic and disease-related variables were expressed in the number and percentage, and the mean and the standard deviation. The chi-square test was used for the univariate analysis. Significances of differences between the mean values of two independent groups were analyzed using Student's t-test. One-way analysis of variance (ANOVA) test was used for analysis of the differences in mean values among three independent groups. The post-hoc Tukey test was applied to analyze the group which was responsible for the difference. Paired t-test was used in the groups paired as pre-and post-treatment. The statistical significance was accepted when P value $<0.05$.

\section{Results}

\subsection{Sociodemographic Characteristics}

The severity of asthmatic attacks in the 80 patients was distributed as follows: 28 (35\%) mild, 26 (32.5\%) moderate, and $26(32.5 \%)$ severe. $51.2 \%$ of the patients were males $(\mathrm{n}=$ 41 ), and $48.7 \%$ females ( $n=39$ ). Age, weight, height, BMI, blood pressure, and heart rate did not differ statistically between groups (Table 1). Allergic rhinitis was associated with asthma in $40 \%(n=32)$ of the patients and atopic dermatitis was diagnosed in $5 \%(n=4)$.

\subsection{Clinical Asthma Characteristics}

Of the 80 patients with asthma, 18 had a mean duration of diagnosis of $4 \pm 1.5$ (2 to 8 ) years with a mean follow-up of $3.2 \pm 2.1$ ( 1 to 9 ) years. The rest of the patients including 62 patients were those recently diagnosed and scheduled for being followed. None of the patients with asthma received inhaled steroids, systemic steroids or leukotriene receptor antagonists during the study.

\subsection{Echocardiographic DATA}

No statistically significant difference was found in the comparison of RVedD, RVesD, IVS, and TAPSE between groups $(\mathrm{P}>0.05)$ (Table 2$)$.

Pre- and post-treatment values of PAcT and mPAP determined by conventional DE did not differ significantly in the group existing with mild asthmatic attacks $(\mathrm{P}=0.86)$. Pre- and post-treatment values of PAcT and mPAP showed a statistically significant difference in the group with moderate asthmatic attacks $(\mathrm{P}=0.031$ and $\mathrm{P}=0.030$, respectively). Similarly, PAcT and mPAP values determined in the pre-and post-treatment periods revealed a statistically significant difference in the group with severe asthmatic attacks $(\mathrm{P}<0.001)$ (Table 3$)$.

When pre-treatment mPAP values were compared between the three groups, it was found to be significantly lower in the group with mild asthmatic attacks, compared to the groups existing with moderate and severe asthmatic attacks $(\mathrm{P}<0.01$ and $\mathrm{P}<0.001$, respectively). However, pretreatment mPAP value did not differ significantly when the groups with moderate and severe asthmatic attacks were compared with each other $(\mathrm{P}=0.521)$ (Table 3$)$.

When the RV functions were evaluated by TDI; Am and Em waves, and IVRT, IVCT, ET and RV MPI values determined during the asthmatic attack and after treatment did not differ significantly between the groups (Table 4).

When the ET-1 and PDGF-BB levels in EBC were evaluated; ET-1 value in the group with severe asthmatic attacks was found to be significantly higher compared to the groups with mild and moderate asthmatic attacks ( $P$ $=0.002$ ). PDGF-BB value in the group with severe attacks was also significantly higher, compared to the group with mild attacks $(\mathrm{P}=0.008)$. PDGF-BB value did not show significant difference between the groups with severe and moderate asthmatic attacks; however a borderline P value was detected (0.051) (Table 5).

\section{Discussion}

In this study, before the treatment in moderate and severe asthma group mPAP was significantly higher than 
Table 1. Overall Characteristics of the Study Population ${ }^{\mathrm{a}}$

\begin{tabular}{|c|c|c|c|c|}
\hline & Mild Asthma Attack $(n=28)$ & Moderate Asthma Attack $(n=26)$ & Severe Asthma Attack $(n=26)$ & P Value \\
\hline Age, $y$ & $10.5 \pm 2.2$ & $8.5 \pm 2.7$ & $9.8 \pm 3.1$ & $>0.05$ \\
\hline Sex (male/female) & $13 / 15$ & $14 / 12$ & $14 / 12$ & \\
\hline Weight, kg & $34.1 \pm 12.5$ & $33.5 \pm 17.9$ & $36.4 \pm 19.8$ & $>0.05$ \\
\hline Height, cm & $124.6 \pm 16.6$ & $122.1 \pm 14.5$ & $125.3 \pm 17.2$ & $>0.05$ \\
\hline BMI, $\mathrm{kg} / \mathrm{m}^{2}$ & $22.0 \pm 4.2$ & $22.4 \pm 4.6$ & $23.1 \pm 3.7$ & $>0.05$ \\
\hline SBP, mmHg & $102.6 \pm 11.8$ & $107.6 \pm 11.1$ & $108.7 \pm 12.5$ & $>0.05$ \\
\hline DBP, mmHg & $69.2 \pm 9.7$ & $66.7 \pm 10.8$ & $73.1 \pm 8.0$ & $>0.05$ \\
\hline Heart rate, beats/min & $78 \pm 21$ & $84 \pm 17$ & $86 \pm 19$ & $>0.05$ \\
\hline FVC, \% predicted & $69 \pm 4.6$ & $55 \pm 5.2$ & $48 \pm 4.6$ & $<0.05$ \\
\hline FEV1, \% predicted & $71 \pm 8.2$ & $65 \pm 6.2$ & $49 \pm 4.5$ & $<0.05$ \\
\hline FEV1/FVC, \% & $75 \pm 6.3$ & $67 \pm 5.5$ & $52 \pm 5.1$ & $<0.05$ \\
\hline
\end{tabular}

Abbreviations: BMI, body mass index; DBP, diastolic blood pressure, FVC, forced vital capacity; FEV1, forced expiratory volume in one second; SBP, systolic blood pressure.

${ }^{\mathrm{a}}$ Values are expressed as mean $\pm \mathrm{SD}$.

Table 2. Right Ventricular Two-Dimensional Echocardiographic Measurements of Groups ${ }^{\mathrm{a}}$

\begin{tabular}{|c|c|c|c|c|c|c|c|}
\hline & \multicolumn{2}{|c|}{ Mild Asthma Attack $(\mathbf{n}=\mathbf{2 8})$} & \multicolumn{2}{|c|}{ Moderate Asthma Attack $(n=26)$} & \multicolumn{2}{|c|}{ Severe Asthma Attack $(n=26)$} & \multirow[t]{2}{*}{ PValue } \\
\hline & Pre-Treatmnet & Post-Treatment & Pre-Treatmnet & Post-Treatment & Pre-Treatmnet & Post-Treatment & \\
\hline RVedD, mm & $30.7 \pm 3.6$ & $30.2 \pm 4.0$ & $29.3 \pm 3.3$ & $29.9 \pm 4.4$ & $30.0 \pm 3.6$ & $29.1 \pm 4.4$ & $>0.05$ \\
\hline RVesD, mm & $20.8 \pm 1.8$ & $20.0 \pm 3.1$ & $20.5 \pm 2.0$ & $21.0 \pm 3.2$ & $20.4 \pm 2.8$ & $20.1 \pm 2.4$ & $>0.05$ \\
\hline IVS, mm & $4.89 \pm 1.0$ & $4.80 \pm 0.7$ & $4.22 \pm 0.7$ & $4.70 \pm 0.9$ & $4.66 \pm 0.9$ & $4.85 \pm 1.1$ & $>0.05$ \\
\hline TAPSE, mm & $21.05 \pm 3.7$ & $22.03 \pm 2.9$ & $20.68 \pm 3.1$ & $21.18 \pm 2.6$ & $21.17 \pm 3.3$ & $21.69 \pm 2.1$ & $>0.05$ \\
\hline
\end{tabular}

Table 3. Pulmonary Flow Evaluations and mPAP Values Obtained by Conventional Doppler Echocardiography ${ }^{\mathrm{a}, \mathrm{b}}$

\begin{tabular}{|c|c|c|c|c|}
\hline & & Pre-Tratment & Post-Treatment & PValue \\
\hline \multirow{3}{*}{ PAcT, msn } & Mild asthma attack $(\mathrm{n}=28)$ & $127.4 \pm 16.2$ & $128.2 \pm 16.2$ & 0.86 \\
\hline & Moderate asthma attack $(n=26)$ & $108.4 \pm 21.9$ & $119.1 \pm 10.5$ & 0.031 \\
\hline & Severe asthma attack $(n=26)$ & $102.8 \pm 17.4$ & $124.3 \pm 15.3$ & $<0.01$ \\
\hline \multirow{3}{*}{ mPAP, mmHg } & Mild asthma attack $(\mathrm{n}=28)$ & $21.6 \pm 7.3$ & $21.3 \pm 7.3$ & 0.86 \\
\hline & Moderate asthma attack $(n=26)$ & $30.1 \pm 9.8$ & $25.3 \pm 4.7$ & 0.030 \\
\hline & Severe asthma attack $(n=26)$ & $32.7 \pm 7.8$ & $23.1 \pm 6.8$ & $<0.01$ \\
\hline
\end{tabular}

Abbreviations: mPAP, mean pulmonary artery pressure; PAcT, acceleration time.

${ }^{\mathrm{a}}$ Values are expressed as mean $\pm \mathrm{SD}$.

${ }^{\mathrm{b}}$ Before the treatment in moderate and severe asthma group mPAP was significantly higher than mild asthma group $(\mathrm{P}=0.01, \mathrm{P}=0.00$, respectively). No significant difference was detected between moderate and severe asthma group $(\mathrm{P}=0.521)$.

mild asthma group. After the treatment no significant difference was detected between asthma groups. Exhaled air samples evaluated ET-1 and PDGF-BB compared with the group with severe asthma exacerbations was higher than the moderate and mild group. Am and Em waves, IVRT, IVCT, ET and RV MPI values during the asthmatic attack and after treatment did not differ significantly between the groups; pre- and post-treatment values of these param- 
Table 4. RV TDI Values of Groups

\begin{tabular}{|c|c|c|c|c|c|c|c|}
\hline & & $\begin{array}{c}\text { Mild Asthma } \\
\text { Attack }(n=28)\end{array}$ & PValue & $\begin{array}{c}\text { Moderate } \\
\text { Asthma Attack } \\
\quad(\mathbf{n}=\mathbf{2 6})\end{array}$ & PValue & $\begin{array}{l}\text { Severe Asthma } \\
\text { Attack }(n=26)\end{array}$ & P Value \\
\hline \multirow{2}{*}{$\mathrm{E}, \mathrm{cm} / \mathrm{sn}$} & Pre-treatment & $17 \pm 2.7$ & \multirow{2}{*}{$>0.05$} & $18.4 \pm 4.0$ & \multirow{2}{*}{$>0.05$} & $16.5 \pm 3.1$ & \multirow{2}{*}{$>0.05$} \\
\hline & Post-treatmen & $16.7 \pm 2.4$ & & $16.1 \pm 3.2$ & & $15.7 \pm 3.0$ & \\
\hline \multirow{2}{*}{$\mathrm{A}, \mathbf{c m} / \mathbf{s n}$} & Pre-treatment & $11.4 \pm 3.3$ & $>0.05$ & $12.1 \pm 3.7$ & \multirow{2}{*}{$>0.05$} & $12.3 \pm 4.2$ & \multirow{2}{*}{$>0.05$} \\
\hline & Post-treatment & $10.8 \pm 2.2$ & & $10.9 \pm 2.6$ & & $11.6 \pm 3.7$ & \\
\hline \multirow{2}{*}{ IVRT, msn } & Pre-treatment & $51.1 \pm 9.4$ & \multirow{2}{*}{$>0.05$} & $44.9 \pm 9.3$ & \multirow{2}{*}{$>0.05$} & $44.3 \pm 9.1$ & \multirow{2}{*}{$>0.05$} \\
\hline & Post-treatment & $50.1 \pm 4.9$ & & $46.8 \pm 5.6$ & & $46.0 \pm 8.7$ & \\
\hline \multirow{2}{*}{ IVCT, msn } & Pre-treatment & $52.5 \pm 10.0$ & \multirow{2}{*}{$>0.05$} & $45.7 \pm 8.3$ & $>0.05$ & $46.4 \pm 7.1$ & \multirow{2}{*}{$>0.05$} \\
\hline & Post-treatment & $51.1 \pm 7.5$ & & $46.8 \pm 6.0$ & & $52.1 \pm 7.5$ & \\
\hline \multirow{2}{*}{ ET, msn } & Pre-treatment & $251 \pm 29.2$ & \multirow{2}{*}{$>0.05$} & $239.0 \pm 47.1$ & \multirow{2}{*}{$>0.05$} & $232.7 \pm 26.3$ & \multirow{2}{*}{$>0.05$} \\
\hline & Post-treatment & $253.8 \pm 27.3$ & & $244.8 \pm 25.5$ & & $255.2 \pm 22.0$ & \\
\hline \multirow{2}{*}{ MPI } & Pre-treatment & $0.41 \pm 0.06$ & \multirow{2}{*}{$>0.05$} & $0.38 \pm 0.08$ & \multirow{2}{*}{$>0.05$} & $0.39 \pm 0.07$ & \multirow{2}{*}{$>0.05$} \\
\hline & Post-treatment & $0.39 \pm 0.06$ & & $0.38 \pm 0.04$ & & $0.38 \pm 0.04$ & \\
\hline
\end{tabular}

Abbreviations: Am, late diastolic myocardial velocity; ET, ejection time; Em, early diastolic myocardial velocity; IVRT, isovolumic relaxation time; IVCT, isovolumic contraction time; MPI, myocardial performance index; Sm, systolic myocardial velocity.

${ }^{a}$ Values are expressed as mean $\pm S D$.

Table 5. Cytokine Values of Groups ${ }^{\mathrm{a}}$

\begin{tabular}{lccc}
\hline & Mild Asthma $(\mathbf{n}=\mathbf{2 8})$ & Moderate Asthma $(\mathbf{n}=\mathbf{2 6})^{\text {P Value }^{\mathrm{b}}}$ & Severe Astma $(\mathbf{n}=\mathbf{2 6})$ \\
\hline Endotelin-1, pg/mL & $0.50 \pm 0.15$ & $0.58 \pm 0.30$ & $0.80 \pm 0.42^{\mathrm{c}}$ \\
PDGF-BB, pg/mL & $135.9 \pm 74.9$ & $167.3 \pm 148.1$ & $281.7 \pm 253.2^{\mathrm{c}}$ \\
\hline
\end{tabular}

Abbreviations: PDGF-BB, platelet derived growth factor-BB.

${ }^{\mathrm{a}}$ Values are expressed as mean $\pm \mathrm{SD}$.

b One-way ANOVA testi,

${ }^{c}$ Group that makes a difference according to Post hoc Tukey.

eters were also not found to differ significantly within each separate group.

In the previous studies performed by echocardiography in the cases with asthma, left and right ventricular diastolic dysfunction was found to develop particularly in the patients with severe asthma. RV diastolic dysfunction has been reported to be related with RV hypertrophy and total pulmonary resistance $(16,17)$. RV diastolic parameters in the children with moderate asthma were determined before and after the treatment of inhaled steroid, in a study performed by conventional $\mathrm{DE}$, and parameters of RV diastolic filling were found to improve markedly after treatment (18). In our study, M-mode measurements (RVedD, RVesD and IVS) did not differ significantly between the groups (Table 2).

Cardiac catheterization is the gold standard for measurement of RV pressure and MPAP. The PAcT value, which is measured for estimation of pulmonary arterial pressure
(PAP), may provide important information about mPAP. Previous studies have stated a negative correlation between MPAP and PAcT (19). In our study, Mahan formula was used for calculation through the PAcT $(11,12)$. Increased PAP as the attack severity increases is an expected consequence of asthma. In our study, before the treatment in moderate and severe asthma group mPAP was significantly higher than in mild asthma group. No significant difference was detected between moderate and severe asthma group. In moderate and severe asthma group, PAcT was significantly lower than in mild asthma group. After the treatment mPAP and PAcT values in the groups were similar (Table 3). Bagnato et al. suggested that shortening in PAcT might be an early sign of right ventricular systolic dysfunction, before the diastolic dysfunction develops (20). Increased mPAP in our study might be associated with the changes in Em and Am waves, as well as IVCT, IVRT and MPI values; however, we did not find significant differences in 
these values. This may be due to the fact that these evaluations were performed when the patients were admitted due to their respiratory complaints they had no frequent attacks previously.

On the other hand, TAPSE is a quite useful method for evaluation of RV systolic function with M-mode echo which is particularly well-correlated with RVEF and measured by radionuclide method $(14,15,21)$. Being an easily applicable and measurable parameter that demonstrates the ineffectiveness of heart rate in children on longitudinal motion of atrioventricular annulus, it increases TAPSEs' applicability in pediatric patients (22). In our study, no differences existed in TAPSE measurements between the groups. This indicates that changes to a degree which could affect the right ventricular functions did not exist in the patients.

The RV diastolic dysfunction is the earliest hemodynamic change in cases with asthma. RV dysfunction is related with the RV hypertrophy and pulmonary resistance (18). TDI gives the chance of possibility to evaluate both systolic and diastolic functions independently from ventricular geometry and partially from volume load (23). The studies that evaluated TDI measurement in patients with asthma found decreased Em, Am, and Sm waves and shortened ET with concomitant prolongation in IVRT and consequent prolongation in MPI (24). As an indication of diastolic dysfunction, the prolonged IVRT and decreased Em are the signs of delay in RV relaxation. Decreased Am velocity is a sign of restrictive RV physiology. Elongation in IVCT is a sign of systolic activation delay (25). MPI is a reliable and useful index which can show information about the global RV function (26). MPI increases in diseases with $\mathrm{RV}$ dysfunction. In the study of Uyan et al. ventricular functions of 90 children with asthma were evaluated with DE and right and left ventricular diastolic dysfunctions were determined in the groups with moderate and severe asthma (18). Evaluation of RV by TDI revealed no significant statistical differences between the groups in the pre- and post-treatment periods regarding IVRT, IVCT, Em, Am, ET and MPI (Table 4). Patients included in our study had acute attacks, and most (77.5\%) of them were the cases diagnosed initially. Nonsignificant differences in the results revealed by TDI values, patients with averagely short follow-up durations, and low mean age values of the patients made us consider that asthma might not exert its effects on the cardiac functions.

There is a limited number of data on the specific role of PDGF on the cardiac myocytes. Most of the studies evaluating PDGF in the literature are conducted with animal models in which fibrosis and proliferation in the vascular smooth muscle cells were investigated. Fibroblasts are the primary source of hyaluronic acid which plays an impor- tant role in the cardiac hypertrophy, and PDGF-BB levels were shown to correlate with the levels of hyaluronic acid $(27,28)$.

Endothelins are naturally produced in the body and they are known to be the most potent vasoconstrictor molecules. Hypoxia is one of the various factors which affect the release of ET. In the studies performed with animal models, ET-1 infusion was shown to produce ventricular dysfunction, myocardial infarction and arrhythmias (29, 30). ET-1 levels in the arterial blood and exhaled air were shown to be significantly higher in the patients with pulmonary arterial hypertension, and it was reported to be a helpful method in diagnosis of the critical disease and starting the treatment (31). A negative correlation was reported in the literature between the plasma oxygen levels and ET in humans. Decreased PAP following oxygen administration was reported to be associated with decrease in plasma ET (32).

In our study, ET-1 and PDGF-BB levels in the EBC samples were determined to be significantly higher in the group with severe asthmatic attacks, compared to the groups existing with mild and moderate asthmatic attacks.

Inflammatory response exists in tissues in the patients with asthma which depends on the degree of hypoxia, and tissue damage is produced related to the severity of the response. As also shown in the literature, our analysis in the inflamed tissue indicated that PDGF-BB and ET-1 levels increased in the damaged tissue, which was directly proportional to the attack severity. These cytokines play a role in the embryonic development and the existing pathological conditions, and evaluation of them in the children exposed to acute and chronic effects of asthma disease which frequently exist in the population, may be an important prognostic indicator. We found that depending on the attack severity, mPAP values increased in proportion to the increases in cytokine levels, and this result is in accordance with the literature. The increase in mPAP with the increase in attack severity, and the parallely increasing cytokine levels, are significant indicators showing that cardiac effects exist in this period to play role in the increased mPAP.

In addition, there is a limited number of studies investigating the direct cardiac effects of cytokines that are produced during the asthmatic episode in the literature. High levels of ET and PDGF-BB were shown to increase cardiac damage in the animal models (33). This indicates that the effect of cytokines on the pulmonary arteriolar system causes an increased cardiac load, and thus, indirectly produces this effect on the heart. Besides, we conclude that cytokines may worsen the myocardial damage by their direct effect on the heart.

This study was planned due to these considerations and these effects and interactions should be kept in mind 
during clinical evaluation which may lead to the existence of new options in the prediction of prognosis and in the application of treatment methods in asthma disease that exists with an extremely high incidence and prevalence. In the present study, we showed that non-invasive evaluation of mPAP by echocardiography during an acute asthmatic episode is a method with a high clinical value, and also that high cytokine levels are correlated with the increased mPAP values, in consistent with the literature data. Parameters which showed diastolic functions determined by DE were found to be normal. We found that increased ET-1 and PDGF-BB levels in the exhaled air do not produce diastolic dysfunction. However, the following factors may also contribute to the existing results: patients included in our study had not chronically increased afterload, most of the patients were recently considered for being followed-up in our clinic, and had less numbers of acute attacks, which is a characteristic of asthma disease. In addition, response of asthmatic attacks to treatment was found to be successful in the controls in the vast majority of cases, and this also indicates that the heart was not exposed to an effect and extra work which would lead to diastolic dysfunction.

In conclusion, application of non-invasive methods in the collection of samples and evaluation of effects during a study would be advantageous in maintaining the patient's comfort and cooperation. In the present study, no systolic or diastolic dysfunction was determined in the cardiac evaluations during the asthmatic attacks; however, mPAP was found to increase in the cases with moderate and severe asthma. Levels of ET- 1 and PDGF, which are the biomarkers released as a response to vascular stress, were evaluated in the EBC; this is another non-invasive method, and these markers were found to increase significantly with the increased severity of asthmatic attacks.

\section{References}

1. Ishmael FT. The inflammatory response in the pathogenesis of asthma. J Am Osteopath Assoc. 2011;111(11 Suppl 7):S11-7. [PubMed: 22162373].

2. Woods BD, Sladen RN. Perioperative considerations for the patient with asthma and bronchospasm. BrJ Anaesth. 2009;103 Suppl 1:i5765. doi: 10.1093/bja/aep271. [PubMed: 20007991].

3. Global Strategy for Asthma Management and Prevention . Asthma 2010. Available from: http://www.ginasthma.org/local/uploads/files/ GINA_Report_2010_1.pdf.

4. Shedeed SA. Right ventricular function in children with bronchial asthma: a tissue Doppler echocardiographic study. Pediatr Cardiol. 2010;31(7):1008-15. doi: 10.1007/s00246-010-9753-2. [PubMed: 20697704].

5. Leung TF, Wong GW, Ko FW, Li CY, Yung E, Lam CW, et al. Analysis of growth factors and inflammatory cytokines in exhaled breath condensate from asthmatic children. Int Arch Allergy Immunol. 2005;137(1):66-72. doi:10.1159/000085106. [PubMed: 15832052].

6. Horvath I, Hunt J, Barnes PJ, Alving K, Antczak A, Baraldi E, et al. Exhaled breath condensate: methodological recommendations and unresolved questions. Eur Respir J. 2005;26(3):523-48. doi: 10.1183/09031936.05.00029705. [PubMed: 16135737].

7. Zietkowski Z, Skiepko R, Tomasiak MM, Bodzenta-Lukaszyk A. Endothelin-1 in exhaled breath condensate of allergic asthma patients with exercise-induced bronchoconstriction. Respir Res. 2007;8:76. doi: 10.1186/1465-9921-8-76. [PubMed:17973986].

8. Bateman ED, Hurd SS, Barnes PJ, Bousquet J, Drazen JM, FitzGerald $\mathrm{M}$, et al. Global strategy for asthma management and prevention: GINA executive summary. Eur Respir J. 2008;31(1):143-78. doi: 10.1183/09031936.00138707. [PubMed: 18166595].

9. Ueti OM, Camargo EE, Ueti Ade A, de Lima-Filho EC, Nogueira EA. Assessment of right ventricular function with Doppler echocardiographic indices derived from tricuspid annular motion: comparison with radionuclide angiography. Heart. 2002;88(3):244-8. [PubMed: 12181215].

10. Dabestani A, Mahan G, Gardin JM, Takenaka K, Burn C, Allfie A, et al. Evaluation of pulmonary artery pressure and resistance by pulsed Doppler echocardiography. Am J Cardiol. 1987;59(6):662-8. [PubMed: 3825910].

11. Mahan G, Dabestani A, Gardin JM, Allfie A, Burn C, Henry WL. Estimation of pulmonary-artery pressure by pulsed doppler echocardiography. Circulation. 1983;68(4):367.

12. Kitabatake A, Inoue M, Asao M, Masuyama T, Tanouchi J, Morita T, et al. Noninvasive evaluation of pulmonary hypertension by a pulsed Doppler technique. Circulation. 1983;68(2):302-9. [PubMed: 6861308].

13. Laaban JP, Diebold B, Zelinski R, Lafay M, Raffoul H, Rochemaure J. Noninvasive estimation of systolic pulmonary artery pressure using Doppler echocardiography in patients with chronic obstructive pulmonary disease. Chest. 1989;96(6):1258-62. [PubMed: 2582830].

14. Lang RM, Bierig M, Devereux RB, Flachskampf FA, Foster E, Pellikka PA, et al. Recommendations for chamber quantification: a report from the American Society of Echocardiography's Guidelines and Standards Committee and the Chamber Quantification Writing Group, developed in conjunction with the European Association of Echocardiography, a branch of the European Society of Cardiology. J Am Soc Echocardiogr. 2005;18(12):1440-63. doi:10.1016/j.echo.2005.10.005. [PubMed: 16376782].

15. Rudski LG, Lai WW, Afilalo J, Hua L, Handschumacher MD, Chandrasekaran K, et al. Guidelines for the echocardiographic assessment of the right heart in adults: a report from the American Society of Echocardiography endorsed by the European Association of Echocardiography, a registered branch of the European Society of Cardiology, and the Canadian Society of Echocardiography. J Am Soc Echocardiogr. 2010;23(7):685-713. doi: 10.1016/j.echo.2010.05.010. [PubMed: 20620859] quiz 786-8

16. Chicherina EN, Shipitsyna VV. [The cardiovascular system in patients with bronchial asthma of varying severity]. Probl Tuberk Bolezn Legk. 2003(8):25-8. [PubMed: 14524096].

17. Eniseeva ES, Sizykh TP. [The hemodynamic status and right ventricular diastolic function of bronchial asthma patients]. Ter Arkh. 1995;67(8):39-42. [PubMed: 7482332].

18. Uyan AP, Uyan C, Ozyurek H. Assessment of right ventricular diastolic filling parameters by Doppler echocardiography. Pediatr Int. 2003;45(3):263-7. [PubMed: 12828578].

19. Bossone E, Bodini BD, Mazza A, Allegra L. Pulmonary arterial hypertension: the key role of echocardiography. Chest. 2005;127(5):1836-43. doi: 10.1378/chest.127.5.1836. [PubMed: 15888866].

20. Bagnato GF, Mileto A, Gulli S, Piscioneri S, Romano C, Giacobbe $\mathrm{O}$, et al. Non invasive assessment of cardiac function in patients with bronchial asthma (BA) or chronic obstructive pulmonary disease (COPD). Allergol Immunopathol (Madr). 1999;27(1):5-10. [PubMed: 10217666].

21. Miller D, Farah MG, Liner A, Fox K, Schluchter M, Hoit BD. The relation between quantitative right ventricular ejection fraction and indices of tricuspid annular motion and myocardial performance. $J$ 
Am Soc Echocardiogr. 2004;17(5):443-7. doi: 10.1016/j.echo.2004.01.010. [PubMed: 15122184].

22. Koestenberger M, Nagel B, Ravekes W, Everett AD, Stueger HP, Heinzl $B$, et al. Systolic right ventricular function in pediatric and adolescent patients with tetralogy of Fallot: echocardiography versus magnetic resonance imaging. J Am Soc Echocardiogr. 2011;24(1):45-52. doi: 10.1016/j.echo.2010.10.001. [PubMed: 21074365].

23. Eidem BW, McMahon CJ, Cohen RR, Wu J, Finkelshteyn I, Kovalchin JP, et al. Impact of cardiac growth on Doppler tissue imaging velocities: a study in healthy children. J Am Soc Echocardiogr. 2004;17(3):212-21. doi: 10.1016/j.echo.2003.12.005. [PubMed: 14981417].

24. Ozdemir O, Ceylan Y, Razi CH, Ceylan O, Andiran N. Assessment of ventricular functions by tissue Doppler echocardiography in children with asthma. Pediatr Cardiol. 2013;34(3):553-9. doi: 10.1007/s00246012-0493-3. [PubMed: 22965765].

25. Yasuoka K, Harada K, Toyono M, Tamura M, Yamamoto F. Tei index determined by tissue Doppler imaging in patients with pulmonary regurgitation after repair of tetralogy of Fallot. Pediatr Cardiol. 2004;25(2):131-6. doi: 10.1007/s00246-003-0514-3. [PubMed: 14648001].

26. Schwerzmann M, Samman AM, Salehian O, Holm J, Provost Y, Webb GD, et al. Comparison of echocardiographic and cardiac magnetic resonance imaging for assessing right ventricular function in adults with repaired tetralogy of fallot. Am J Cardiol. 2007;99(11):1593-7. doi: 10.1016/j.amjcard.2007.01.035. [PubMed: 17531587].
27. Fontaine ER, Viau S, Jasmin G, Dumont L. Effects of phosphoramidon, BQ 788, and BQ 123 on coronary and cardiac dysfunctions of the failing hamster heart. J Cardiovasc Pharmacol. 1998;32(1):12-20. [PubMed: 9676715].

28. Sakai S, Miyauchi T, Sakurai T, Kasuya Y, Ihara M, Yamaguchi I, et al. Endogenous endothelin-1 participates in the maintenance of cardiac function in rats with congestive heart failure. Marked increase in endothelin-1 production in the failing heart. Circulation. 1996;93(6):1214-22. [PubMed: 8653844].

29. Tamirisa P, Frishman WH, Kumar A. Endothelin and endothelin antagonism: roles in cardiovascular health and disease. Am Heart J. 1995;130(3 Pt 1):601-10. [PubMed: 7661079].

30. Hirata Y. Endothelin peptides. Curr Opin Nephrol Hypertens, 1996;5(1):12-5. [PubMed: 8834156].

31. Carratu P, Scoditti C, Maniscalco M, Seccia TM, Di Gioia G, Gadaleta $\mathrm{F}$, et al. Exhaled and arterial levels of endothelin-1 are increased and correlate with pulmonary systolic pressure in COPD with pulmonary hypertension. BMC Pulm Med. 2008;8:20. doi: 10.1186/1471-2466-8-20. [PubMed: 18822124].

32. Goerre S, Wenk M, Bartsch P, Luscher TF, Niroomand F, Hohenhaus E, et al. Endothelin-1 in pulmonary hypertension associated with highaltitude exposure. Circulation. 1995;91(2):359-64. [PubMed: 7805238].

33. Myrianthefs MM, Zambartas CM. Acute, reversible myocardial is chemia in a patient with an asthmatic attack. J Electrocardiol. 1996;29(4):337-9. [PubMed: 8913909]. 